\title{
JN $\mathrm{N}$

April 7, $2021 \bullet$ Volume 41 Number $14 \bullet$ www.jneurosci.org

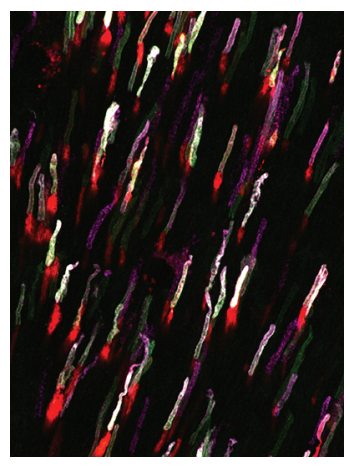

Cover legend: This image shows photoreceptor neurons in a mouse retina. A subset of rod photoreceptors are labeled with $\mathrm{mCherry}$ (red) and are expressing the alpha (magenta) and beta (green) subunits of the rod cyclic nucleotide-gated channel. For more information, see the article by Pearring et al. on pages 3094-3104. Cover image: Jillian Pearring.
3039 This Week in The Journal

\section{Viewpoints}

3040 Regulation of Synaptic Transmission and Plasticity by Protein Phosphatase 1 Karl Foley, Cody McKee, Angus C. Nairn, and Houhui Xia

\section{Journal Club}

3051 Disentangling the Association between the Insula and the Autonomic Nervous System

Daniel Roquet and Federica Conti

\section{Research Articles}

\section{CELLULAR/MOLECULAR}

3054 Changes in Presynaptic Gene Expression during Homeostatic Compensation at a Central Synapse

Evan R. Harrell, Diogo Pimentel, and Gero Miesenböck

3068 Abl2:Cortactin Interactions Regulate Dendritic Spine Stability via Control of a Stable Filamentous Actin Pool

Juliana E. Shaw, Michaela B.C. Kilander, Yu-Chih Lin, and Anthony J. Koleske

3082 The WD40-Repeat Protein WDR-20 and the Deubiquitinating Enzyme USP-46 Promote Cell Surface Levels of Glutamate Receptors

Molly Hodul, Bethany J. Rennich, Eric S. Luth, Caroline L. Dahlberg, and Peter Juo

3094 The GARP Domain of the Rod CNG Channel's $\beta 1$-Subunit Contains Distinct Sites for Outer Segment Targeting and Connecting to the Photoreceptor Disk Rim Jillian N. Pearring, Jorge Martínez-Márquez, Jason R. Willer, Eric C. Lieu, Raquel Y. Salinas, and Vadim Y. Arshavsky

\section{DEVELOPMENT/PLASTICITY/REPAIR}

3105 Interneuron Origins in the Embryonic Porcine Medial Ganglionic Eminence Mariana L. Casalia, Tina Li, Harrison Ramsay, Pablo J. Ross, Mercedes F. Paredes, and Scott C. Baraban

\section{SYSTEMS/CIRCUITS}

3120 Adult trkB Signaling in Parvalbumin Interneurons is Essential to Prefrontal Network Dynamics

Nicolas Guyon, Leonardo Rakauskas Zacharias, Josina Anna van Lunteren, Jana Immenschuh, Janos Fuzik, Antje Märtin, Yang Xuan, Misha Zilberter, Hoseok Kim, Konstantinos Meletis, Cleiton Lopes-Aguiar, and Marie Carlén 
3142 Diversity of Receptive Fields and Sideband Inhibition with Complex Thalamocortical and Intracortical Origin in L2/3 of Mouse Primary Auditory Cortex Ji Liu and Patrick O. Kanold

3163 The Myelin Content of the Human Precentral Hand Knob Reflects Interindividual Differences in Manual Motor Control at the Physiological and Behavioral Level Raffaele Dubbioso, Kristoffer Hougaard Madsen, Axel Thielscher, and Hartwig Roman Siebner

\section{BEHAVIORAL/COGNITIVE}

3180 Spatially Guided Distractor Suppression during Visual Search Tobias Feldmann-Wüstefeld, Marina Weinberger, and Edward Awh

3192 Visuo-Motor Feedback Modulates Neural Activities in the Medulla of the Honeybee, Apis mellifera

Claire Rusch, Diego Alonso San Alberto, and Jeffrey A. Riffell

3204 Increased Hippocampal Excitability and Altered Learning Dynamics Mediate Cognitive Mapping Deficits in Human Aging

Nadine Diersch, Jose P. Valdes-Herrera, Claus Tempelmann, and Thomas Wolbers

3222 Human Sensory Cortex Contributes to the Long-Term Storage of Aversive Conditioning

Yuqi You, Joshua Brown, and Wen Li

3234 Variable Statistical Structure of Neuronal Spike Trains in Monkey Superior Colliculus

Seong-Hah Cho, Trinity Crapse, Piercesare Grimaldi, Hakwan Lau, and Michele A. Basso

3254 Dynamics of Heading and Choice-Related Signals in the Parieto-Insular Vestibular Cortex of Macaque Monkeys

Aihua Chen, Fu Zeng, Gregory C. DeAngelis, and Dora E. Angelaki

3266 Brain Activity Foreshadows Stock Price Dynamics

Mirre Stallen, Nicholas Borg, and Brian Knutson

\section{NEUROBIOLOGY OF DISEASE}

3275 Reduction of Glut1 in the Neural Retina But Not the RPE Alleviates Polyol Accumulation and Normalizes Early Characteristics of Diabetic Retinopathy Nicholas C. Holoman, Jacob J. Aiello, Timothy D. Trobenter, Matthew J. Tarchick, Michael R. Kozlowski, Emily R. Makowski, Darryl C. De Vivo, Charandeep Singh, Jonathan E. Sears, and Ivy S. Samuels

Persons interested in becoming members of the Society for Neuroscience should contact the Membership Department at membership@sfn.org or 202-962-4911.

For current submission policies and manuscript preparation guidelines, authors should refer to our Information for Authors at https://www.jneurosci.org/ content/information-authors.

Manuscripts should be submitted online at https://jneurosci.msubmit.net. Please contact the Central Office with any questions at jn@sfn.org or 202-962-4000. 